applications in the management of AA patients. Indeed, deep whole exome sequencing, ${ }^{15} \mathrm{CyTOF}^{14}$ and deep TCR analysis $^{2}$ all help to better describe the pathogenic events underlying bone marrow failure syndromes. Even if none of them translates into immediate therapeutic decisions, they are all useful to confirm the diagnosis, to determine the prognosis and possibly to monitor the clinical course of AA patients. Indeed, this latter application may be useful for early identification of refractory or relapsing patients, paving the way for pre-emptive therapeutic interventions. Moreover, the deep dissection at the clonal and at the functional levels of the immune T-cell compartment (e.g. combining CyTOF and TCR analysis) may also answer some open questions in the field. For example, the differential depletion of some specific T-cell subsets might explain the different outcome seen with different ATG preparations. ${ }^{3}$ These novel technologies may help identify the specific T-cell subsets which are crucial to the pathophysiology of AA (and possibly differentially depleted by distinct ATG brands), possibly driving the development of future targeted therapies.

\section{References}

1. Young NS. Current concepts in the pathophysiology and treatment of aplastic anemia. Hematology Am Soc Hematol Educ Program. 2013;2013:76-81.

2. Giudice V, Feng X, Lin Z, et al. Deep sequencing and flow cytometric characterization of expanded effector memory CD8+CD57+ T cells frequently reveals $\mathrm{T}$-cell receptor Vbeta oligoclonality and CDR3 homology in acquired aplastic anemia. Haematologica. 2018;103(5): 759-769.

3. Scheinberg $\mathrm{P}$, Nunez $\mathrm{O}$, Weinstein $\mathrm{B}$, et al. Horse versus rabbit antithymocyte globulin in acquired aplastic anemia. N Engl J Med. 2011;365(5):430-438.

4. Zoumbos NC, Gascón P, Djeu JY, Trost SR, Young NS. Circulating activated suppressor $\mathrm{T}$ lymphocytes in aplastic anemia. $\mathrm{N}$ Engl J Med. 1985;312(5):257-265.

5. Zoumbos NC, Gascón P, Djeu JY, Young NS. Interferon is a mediator of hematopoietic suppression in aplastic anemia in vitro and possibly in vivo. Proc Natl Acad Sci USA. 1985;82(1):188-192.

6. Sloand E, Kim S, Maciejewski JP, Tisdale J, Follmann D, Young NS
Intracellular interferon-gamma in circulating and marrow $\mathrm{T}$ cells detected by flow cytometry and the response to immunosuppressive therapy in patients with aplastic anemia. Blood. 2002;100(4):11851191.

7. Selleri C, Maciejewski JP, Sato T, Young NS. Interferon-gamma constitutively expressed in the stromal microenvironment of human marrow cultures mediates potent hematopoietic inhibition. Blood: 1996;87(10):4149-4157.

8. Alvarado LJ, Andreoni A, Huntsman HD, et al. Heterodimerization of TPO and IFNy Impairs Human Hematopoietic Stem/Progenitor Cell Signaling and Survival in Chronic Inflammation Blood. 2017;130(Suppl 1):4.

9. Zeng W, Nakao S, Takamatsu H, et al. Characterization of T-cell repertoire of the bone marrow in immune-mediated aplastic anemia: evidence for the involvement of antigen-driven T-cell response in cyclosporine-dependent aplastic anemia. Blood. 1999;93(9):30083016.

10. Risitano AM, Maciejewski JP, Green S, Plasilova M, Zeng W, Young NS. In-vivo dominant immune responses in aplastic anaemia: molecular tracking of putatively pathogenetic T-cell clones by TCR betaCDR3 sequencing. Lancet. 2004;364(9431):355-364.

11. de Latour RP, Visconte V, Takaku T, et al. Th17 immune responses contribute to the pathophysiology of aplastic anemia. Blood. 2010;116(20):4175-4184.

12. Solomou EE, Rezvani K, Mielke S, et al. Deficient CD4+ CD25+ FOXP3 $+\mathrm{T}$ regulatory cells in acquired aplastic anemia. Blood. 2007;110(5):1603-1606.

13. Kordasti S, Marsh J, Al-Khan S, et al. Functional characterization of CD4+ T cells in aplastic anemia. Blood. 2012;119(9):2033-2043.

14. Kordasti S, Costantini B, Seidl T, et al. Deep phenotyping of Tregs identifies an immune signature for idiopathic aplastic anemia and predicts response to treatment. Blood. 2016;128(9):1193-1205.

15. Yoshizato T, Dumitriu B, Hosokawa K, et al. Somatic Mutations and Clonal Hematopoiesis in Aplastic Anemia. N Engl J Med. 2015;373(1):35-47.

16. Cooper JN, Young NS. Clonality in context: hematopoietic clones in their marrow environment. Blood. 2017;130(22):2363-2372.

17. Calis JJ, Rosenberg BR. Characterizing immune repertoires by high throughput sequencing: strategies and applications. Trends Immunol. 2014;35(12):581-590.

18. Sallusto F, Geginat J, Lanzavecchia A. Central memory and effector memory $T$ cell subsets: function, generation, and maintenance. Annu Rev Immunol. 2004;22:745-763

19. Hu X, Gu Y, Wang Y, Cong Y, Qu X, Xu C. Increased CD4+ and $\mathrm{CD} 8+$ effector memory $\mathrm{T}$ cells in patients with aplastic anemia. Haematologica. 2009;94(3):428-429.

20. Hosokawa K, Muranski P, Fenx X, et al. Memory Stem T Cells in Autoimmune Disease: High Frequency of Circulating CD8+ Memory Stem Cells in Acquired Aplastic Anemia. J Immunol. 2016;196(4):1568-1578.

\title{
Hematopoietic stem cell mobilization with plerixafor in sickle cell disease
}

\author{
Matthew M. Hsieh and John F. Tisdale
}

\author{
Cellular and Molecular Therapeutics Section, Sickle Cell Branch, National Heart, Lung, and Blood Institute (NHLBI), National \\ Institutes of Health (NIH), Bethesda, Maryland
}

E-mail: matthewhs@nhlbi.nih.gov

doi:10.3324/haematol.2018.190876

A After more than a half-century since the molecular basis for sickle cell disease (SCD) was described by Linus Pauling and colleagues, we now possess the molecular tools to contemplate a one-time cure through genetic modification of autologous hematopoietic stem cells (HSC). For these promising gene transfer and gene editing strategies to become a reality, a sufficient number of HSC of high purity must be obtained. Filgrastim, or granulocyte colony-stimulating factor, mobilization and apheresis is the standard method for HSC collection in healthy adult donors, yet this approach is associated with high rates of adverse events requiring hospitalization in SCD, including vaso-occlusive crises, multi-organ failure, and even death, prompting our call for a moratorium on its use for HSC mobilization in SCD. ${ }^{1}$ Thus, bone marrow harvesting is the default approach, with evidence supporting its utility in both animal models and in vitro studies utilizing patients' material..$^{2-4}$ However, bone marrow harvest- 
ing employed in an ongoing HSC gene therapy trial was recently recognized to result in suboptimal yields of high purity HSC at the end of collection and processing, along with substantial pain after each harvest, and most subjects required two or three harvests to yield sufficient cell doses for manufacturing. ${ }^{5,6}$

In this issue of the Journal, two groups of investigators report their results using a third approach to HSC collection in SCD through mobilization with an inhibitor of the CXCR4 chemokine receptor, plerixafor. Boulad et al. performed a dose escalation study of plerixafor among a total of 15 SCD patients at steady state.? Ten of the patients were receiving concomitant treatment with hydroxyurea. Only a minority of patients in each cohort achieved the target of $\geq 30 \mathrm{CD} 34^{+}$cells $/ \mu \mathrm{L}$ at $12 \mathrm{~h}$ after the plerixafor injection: three out six at a dose of $80 \mu \mathrm{g} / \mathrm{kg}$, one out of three at a dose of $160 \mu \mathrm{g} / \mathrm{kg}$, and two out of six at a dose of $240 \mu \mathrm{g} / \mathrm{kg}$. Two patients $(15 \%)$ experienced a vaso-occlusive crisis during the study period - one each at 80 and $240 \mu \mathrm{g} / \mathrm{kg}$. None of the patients underwent leukapheresis, thus attribution of these adverse events could be narrowed to plerixafor. On the other hand, LagreslePeyrou et al. reported the outcomes of three patients who received plerixafor at a dose of $240 \mu \mathrm{g} / \mathrm{kg}$. ${ }^{8}$ All three patients received at least 2 months of red cell exchange transfusion to target a sickle hemoglobin $(\mathrm{HbS})$ near $30 \%$ while hydroxyurea was discontinued. The peak CD34 ${ }^{+}$ cell count reached $>75$ cells $/ \mu \mathrm{L}$ at as early as $3 \mathrm{~h}$ after the injection. All three patients also underwent leukapheresis of 15 to $21 \mathrm{~L}$, with a resulting total CD34 cell yield of 4.5 to $5.8 \times 10^{6} \mathrm{cell} / \mathrm{s} / \mathrm{kg}$ and a purity of $80 \%$ to $95 \%$. No pain, vaso-occlusive crises, or sickle-related events were observed in these three patients.

While the number of patients is relatively small in both studies, important lessons relevant to autologous HSC mobilization and collection in SCD with plerixafor can be gleaned. The first lesson regards preparation of the patients. Specifically, stopping hydroxyurea and utilizing red cell transfusions, simple or exchange, to target a $\mathrm{HbS}$ of $30 \%$ were likely key factors in the successful mobilization of the series reported by Lagresle-Peyrou et al. Conversely, the absence of these measures in the study by Boulad et al. may explain why the majority of their patients failed to reach the target $\mathrm{CD} 34^{+}$concentration. This is consistent with prior work demonstrating a lower CD34 ${ }^{+}$cell content in the marrow of SCD patients on hydroxyurea when compared to those not on the drug. ${ }^{3}$ Discontinuation of hydroxyurea combined with scheduled red cell transfusion to keep the $\mathrm{HbS}$ near $30 \%$ may also have improved purity, which was $80 \%$ to $95 \%$ in the study by Lagresle-Peyrou et al., while helping to minimize the risk of sickle cell-related adverse events while hydroxyurea treatment was interrupted. Secondly, leukocyte and neutrophil counts increased 2- to 3-fold just hours after a single injection of plerixafor, even at the lowest dose of $80 \mu \mathrm{g} / \mathrm{kg}$ tested. Although increases of a similar magnitude also occurred with filgrastim, the adverse events seen with filgrastim may have been related to the prolonged duration of 5 to 6 days from filgrastim that led to the high rates of adverse events in the ear- lier reports. We will need more patients to ascertain the contribution of leukocytosis alone and/or the duration of leukocytosis in developing sickle-related complications. Thirdly, only three patients underwent leukapheresis and though adverse events appear acceptable, expanded accrual could capture additional side effects. Furthermore, if patients with SCD do not meet the goal and need additional mobilization and collection, there could be cumulative side effects. Finally, the peak of mobilization of CD $34^{+}$cells appeared to be much earlier, at 3-6 hours. This observation is distinct from that in healthy donors, in whom the peak is observed at 6-12 hours. ${ }^{9}$ Perhaps the chronically hyperproliferative marrow in SCD partly explains this early release of HSC; there could be other factors at play. Regardless, this observation suggests that for optimal collection, apheresis should be started within 4-6 hours of dosing.

As clinical applications of gene transfer and gene editing strategies are being implemented in SCD, obtaining adequate numbers of HSC safely from patients could be the 'bottleneck', preventing broad dissemination of these exciting approaches. The early results provide optimism that mobilization with plerixafor could be a safer and more efficacious alternative for HSC collection to either filgrastim mobilization or bone marrow harvesting, and provide general confidence for the further development of these promising approaches to a one-time cure for SCD.

\section{(C)2017 NIH (National Institutes of Health)}

\section{References}

1. Fitzhugh CD, Hsieh MM, Bolan CD, Saenz C, Tisdale JF. Granulocyte colony-stimulating factor (G-CSF) administration in individuals with sickle cell disease: time for a moratorium? Cytotherapy. 2009;11(4):464-471.

2. Hematti P, Tuchman S, Larochelle A, Metzger ME, Donahue RE, Tisdale JF. Comparison of retroviral transduction efficiency in CD34+ cells derived from bone marrow versus G-CSF-mobilized or G-CSF plus stem cell factor-mobilized peripheral blood in nonhuman primates. Stem Cells. 2004;22(6):1062-1069.

3. Uchida N, Fujita A, Hsieh MM, et al. Bone marrow as a hematopoietic stem cell source for gene therapy in sickle cell disease: evidence from Rhesus and SCD patients. Hum Gene Ther Clin Dev. 2017;28(3):136144.

4. Uchida N, Bonifacino A, Krouse AE, et al. Accelerated lymphocyte reconstitution and long-term recovery after transplantation of lentiviral-transduced rhesus CD34+ cells mobilized by G-CSF and plerixafor. Exp Hematol. 2011;39(7):795-805.

5. Kanter J, Walters MC, Hsieh MM, et al. Interim results from a phase I/II clinical study of lenitoglobin gene therapy for severe sickle cell disease. Blood. 2016;128(22):1176.

6. Leonard A, Bonifacino A, Dominical VM, et al. Bone marrow characterization in sickle cell disease: inflammation and stress erythropoiesis lead to suboptimal CD34 recovery compared to normal volunteer bone marrow. Blood. 2017;130(Suppl 1):966.

7. Boulad F, Shore T, van Besien K, et al. Safety and efficacy of plerixafor dose escalation for the mobilization of CD34+ hematopoietic progenitor cells in patients with sickle cell disease: interim results. Haematologica. 2018;103(5):770-777.

8. Lagresle-Peyrou C, Lefrere F, Magrin E, et al. Plerixafor enables the safe, rapid, efficient mobilization of haematopoietic stem cells in sickle cell disease patients after exchange transfusion. Haematologica. 2018;103(5):778-786.

9. Pantin J, Purev E, Tian X, et al. Effect of high-dose plerixafor on CD34(+) cell mobilization in healthy stem cell donors: results of a randomized crossover trial. Haematologica. 2017;102(3):600-609. 